\title{
Relato de Experiência: Atendimento Fonoaudiológico À Pacientes Submetidos À Laringectomia Total. a Humanização e Reinserção Social do Pré ao Pós-Cirúrgico.
}

\author{
Brito, Christina May Moran de; Senise, Angela Teixeira; Patti, Giuliane de Loreto; \\ Uchiyama, Luciana; Murano, Maria Helena; Gallinucci, Regina \\ Icesp — christina.brito@icesp.org.br
}

Introdução: na cirurgia de Laringectomia Total $(\mathrm{LT})$ retira-se a laringe para tratar tumores de laringe ou hipofaringe, levando a incapacidade de produzir voz pela fonte glótica e ao desvio definitivo da respiração por um traqueostoma. a atuação fonoaudiológica com estes pacientes é fundamental desde o período que antecede a cirurgia até o pós-operatório. a reabilitação fonoaudiológica em grupo, foi uma escolha desta equipe com o intuito de favorecer a interação e a troca de experiências entre os pacientes, facilitar o enfrentamento das dificuldades e a promover a saúde e melhora da qualidade de vida dos pacientes. Objetivo: Descrever a atuação fonoaudiológica com pacientes submetidos à Laringectomia Total (LT) em um hospital oncológico de grande porte, visando sua reinserção na comunidade. Metodologia: Estudo descritivo da atuação fonoaudiológica hospitalar com pacientes submetidos a LT, do período pré-operatório até a reabilitação em grupo. Resultados: a abordagem fonoaudiológica com o paciente LT inicia-se no préoperatório, com orientação, em grupo e em conjunto com equipe multiprofissional, e atendimento individualizado fonoaudiológico, com foco no cuidado e reabilitação da deglutição e voz. no período de internação, no pós-operatório imediato, reforçam-se as orientações prévias e são introduzidos métodos de comunicação alternativa à fala, enquanto o paciente não está apto a iniciar a voz esofágica. Após a alta hospitalar, o paciente é atendido no ambulatório médico de pós-operatório imediato. no mesmo dia, pode realizar avaliação fonoaudiológica ambulatorial e tão logo haja liberação médica, é introduzida a dieta oral e o paciente é direcionado ao grupo para reabilitação. Principais temas abordados: - Comunicação: o Informações e treino das formas de comunicação alaríngea: voz esofágica, eletrolaringe e prótese traqueoesofágica. o Troca de estratégias entre participantes do grupo no treino de voz alaríngea. - Motivação em compartilhar: dificuldades; progressos; e estratégias. - Perda ou redução do olfato e do paladar: o Adaptações no alimento. o Treino da técnica de pressão negativa intraoral. • Aceitação do esquema corporal: o Abordagem pelos cuidados e proteção ao traqueostoma. o Troca de informação sobre produtos e recursos tecnológicos. Conclusão: Observa-se que a intervenção fonoaudiológica ampla a pacientes submetidos à LT é uma experiência que favorece o acolhimento na fase pré e pós-operatória, a reintegração social e a adaptação a novos meios de comunicação.

Brito, Christina May Moran de; Senise, Angela Teixeira; Patti, Giuliane de Loreto; Uchiyama, Luciana; Murano, Maria Helena; Gallinucci, Regina. Relato de Experiência: Atendimento Fonoaudiológico À Pacientes Submetidos À Laringectomia Total. a Humanização e Reinserção Social do Pré ao Pós-Cirúrgico.. In: Anais do Congresso Internacional de Humanidades \& Humanização em Saúde [= Blucher Medical Proceedings, num.2, vol.1]. São Paulo: Editora Blucher, 2014. ISSN 2357-7282 DOI 10.5151/medpro-cihhs-10697 